\title{
Optimization of ultrasound-assisted extraction of flavonoid compounds and their pharmaceutical activity from curry leaf (Murraya koenigii L.) using response surface methodology
}

\author{
Ali Ghasemzadeh ${ }^{1 *}$, Hawa ZE Jaafar ${ }^{1}$, Ehsan Karimi ${ }^{1}$ and Asmah Rahmat ${ }^{2}$
}

\begin{abstract}
Background: Extraction prior to component analysis is the primary step in the recovery and isolation of bioactive phytochemicals from plant materials.

Methods: Response surface methodology was applied to optimize ultrasound-assisted extraction conditions followed by ultra high performance liquid chromatography (UHPLC) to achieve high catechin, myricetin, and quercetin contents, and high antioxidant and anticancer activities in the curry leaf extracts. The antioxidant and anticancer activities of the leaf extracts were determined by the 1,1-diphenyl-2-picryl-hydrazyl (DPPH) and 3-(4,5-dimethylthiazol-2-yl)-2, 5-diphenyltetrazolium bromide (MTT) assays, respectively. The central composite experimental design (3-level, 3 -factorial) was employed to consider the effects of ultrasonic power $(80-150 \mathrm{~W})$, temperature $\left(40-80^{\circ} \mathrm{C}\right)$, and methanol dilution (40-80\%) on the properties of the curry leaf extracts.
\end{abstract}

Results: It was found that ultrasonic power of $145.49 \mathrm{~W}$ at $55.9^{\circ} \mathrm{C}$ with $80 \%$ methanol was the most appropriate set of conditions for the extraction of catechin, myricetin, and quercetin from curry leaves with the consequent high antioxidant activity. Using the optimum extraction conditions, the extraction yields of catechin, myricetin, and quercetin were $0.482,0.517$, and $0.394 \mathrm{mg} / \mathrm{g} \mathrm{DW}$, respectively, and the antioxidant activity was enhanced to $83 \%$. The optimized extract showed more distinct anticancer activity against HeLa cancer cells in a concentration of $67.2 \mu \mathrm{g} / \mathrm{mL}$ $(P<0.01)$ without toxicity to normal cells.

Conclusions: The results indicated that the pharmaceutical quality of curry leaves could be improved significantly by optimizing the extraction process using response surface methodology.

Keywords: Response surface methodology, Ultra high performance liquid chromatography, Ultrasound-assisted, Curry leaf, HeLa cancer, Flavonoids

\section{Background}

Medicinal plants are the richest source of bioactive compounds used in traditional and modern medicine [1]. Flavonoids and phenolics are essential groups of plant phytochemicals with superoxide radical scavenging activity, thereby providing anticancer activity $[2,3]$. In the herbal medicine industry, the extraction process is the important step for the isolation of phytochemicals

\footnotetext{
*Correspondence: alighasemzadeh@upm.edu.my

'Department of Crop Science, Faculty of Agriculture, University Putra Malaysia, 43400 Serdang, Selangor, Malaysia

Full list of author information is available at the end of the article
}

from herbs and spices [4]. Extraction of herbs using an ultrasound-assisted process was recommended previously as a one of the most inexpensive and simplest existing extraction systems, and could be suitably operated rapidly for large-scale preparations [5]. The application of ultrasound helps develop interesting and novel methodologies in food processing; these methodologies are often complementary to classical methods [6]. Ultrasound-assisted extraction can accelerate heat and mass transfer, has been successively used in the extraction field, and is well known to have a significant effect on the rate of various processes in the food industry [7]. Ultrasound 
waves interact with the plant material and alter its physical and chemical properties; furthermore, their cavitational effect facilitates the release of extractable compounds and enhances the mass transport by disrupting the plant cell walls [7]. Previous studies have demonstrated that the extraction yield of flavonoid compounds depends strongly on the extraction technique, solvent polarity, and temperature [8,9]. A developed model is required for optimizing the independent variables in order to get superior extraction yields from herbs. Response surface methodology (RSM) is a collection of statistical and mathematical techniques that are used to optimize the range of variables in various experimental processes to reduce the number of experimental runs, cost, and time, compared to other methods [10,11]. Murraya koenigii (L.), generally known as the curry leaf, or Pokok kari (Daun kari) in Malaysia, is one of the traditional folk remedies that contains several interesting bioactive compounds [12] with anti-tumor [13], antioxidant [14,15], anti-inflammatory [16], anti-hyperglycemic [17], and hypoglycemic effects [18]. Due to the high beneficial value of this crop, research is required to optimize the extraction process to ensure high nutritional and pharmaceutical quality. However, far too little attention has been paid to the optimization of curry leaf extraction in folk medicine. To the best of our knowledge, there have been no studies to optimize the flavonoid extraction from the curry leaf and following that, improvement of the anticancer and antioxidant activities. The current study is designed in order to optimize the ultrasound-assisted extraction conditions of the Malaysian curry leaf (M. koenigii) to achieve high flavonoid contents and high antioxidant and anticancer activity by using response surface methodology with a central composite design.

\section{Methods}

Plant material

Fresh curry leaf samples were obtained from Bachok, Kelantan province, Malaysia. The Malaysian Agriculture Research and Development Institute (MARDI) identified the samples with voucher specimens of MTM0018/1. The leaves were shade-dried (moisture content: 6.2\%), powdered (80 mesh), and kept at $-20^{\circ} \mathrm{C}$.

\section{Ultrasound-assisted extraction}

The curry leaves $(1 \mathrm{~g})$ were mixed with methanol $(20 \mathrm{~mL})$ with different concentrations from $40 \%$ to $80 \%$. The solutions were transferred to an ultrasonic bath. The temperature and ultrasonic power was adjusted from 40 to $80^{\circ} \mathrm{C}$ and 80 to $150 \mathrm{~W}$, respectively. Extraction was conducted for $20 \mathrm{~min}$ under these various conditions. In total, 20 experiments with different variables for extraction were completed (Table 1).

\section{Identification of flavonoids by Ultra High Performance Liquid Chromatography (UHPLC)}

The UHPLC system (Agilent, Model 1200) with a C18 $(4.6 \times 250 \mathrm{~mm}, 5 \mu \mathrm{m})$ column was used for flavonoid separation and identification. In this system, two mobile phases, $0.03 \mathrm{M}$ orthophosphoric acid (A) and HPLCgrade methanol (B), were used. The column temperature, flow rate, and injection volume were adjusted at $35^{\circ} \mathrm{C}$, $20 \mu \mathrm{L}$, and $1 \mathrm{~mL} / \mathrm{min}$, respectively. The range of the detecting wavelength was between 260 and $360 \mathrm{~nm}$. Gradient elution was performed as follows: 0-10 min for $40-100 \% \mathrm{~B}$; $10-15 \mathrm{~min}$ for $100 \% \mathrm{~B}$; $15-20 \mathrm{~min}$ for $100-40 \% \mathrm{~B}$, and finally, washing of the column. To prepare the standard solutions, catechin $(0.0625,0.125$, $0.250,0.500$, and $1 \mathrm{mg} / \mathrm{mL})$, myricetin $(0.031,0.062$, $0.124,0.248$, and $0.496 \mathrm{mg} / \mathrm{mL})$, and quercetin $(0.09$, $0.18,0.36,0.72$ and $1.44 \mathrm{mg} / \mathrm{mL}$ ) were dissolved in the HPLC-grade methanol. The linear regression equation was calculated with $Y=a X \pm b$, where $\mathrm{X}$ is the concentration of flavonoid and $\mathrm{Y}$ is the peak area of flavonoids obtained from UHPLC.

\section{1,1-diphenyl-2-picrylhydrazyl (DPPH) assay}

The free radical scavenging activity of the curry leaf extracts was determined according to the method reported by Mensor et al. [19] with some modification. DPPH was dissolved in methanol to obtain a final concentration of $2 \mathrm{mM}$. Then, the DPPH solution $(1 \mathrm{~mL})$ was added to different concentrations of curry leaf extracts $(20,40,60$ 80 , and $100 \mathrm{mg} / \mathrm{mL}$ ). The mixture was shaken gently and incubated at $28^{\circ} \mathrm{C}$ in a dark room for $40 \mathrm{~min}$. For the control, methanol was used as a blank. The absorbance of the samples was read at $517 \mathrm{~nm}$ using a spectrophotometer. BHT (butylhydroxytoluene) and $\alpha$-tocopherol were used as positive controls. The scavenging activity was calculated using the following formula:

$$
\begin{aligned}
\% \text { inhibition }= & {[\text { (absorbance of control-absorbance of sample }) } \\
& / \text { absorbance of control }] \times 100
\end{aligned}
$$

\section{Determination of anticancer activity}

The frozen cells were retrieved from a liquid nitrogen cell storage tank and thawed rapidly in cryovials. The contents of the cryovial were carefully transferred to a centrifuge tube and a prewarmed media $(10 \mathrm{~mL})$ was gradually added to the cell suspension. The centrifuge tube was spun down at $1000 \mathrm{rpm}$ for $10 \mathrm{~min}$ and the resulting pellet gently resuspended in fresh media $(10 \mathrm{~mL})$ in a culture flask. Subsequent incubation was carried out in a $37^{\circ} \mathrm{C}$ humidified incubator supplemented with $5 \% \mathrm{CO}_{2}$. After $24 \mathrm{~h}$, the old medium was discarded one day after seeding and 2-3 mL PBS was added to cover the entire surface and discard. Then, 1.5-2 mL trypsinizing 
Table 1 Experimental design and observed experimental data

\begin{tabular}{|c|c|c|c|c|c|c|c|c|c|c|c|}
\hline Treatment & Temperature ${ }^{\circ} \mathrm{C}$ & $\begin{array}{c}\text { Methanol } \\
\text { concentration \% }\end{array}$ & $\begin{array}{l}\text { Ultrasunic } \\
\text { power (W) }\end{array}$ & Catechin & Predicted & Myricetin & Predicted & Quercetin & Predicted & Antioxidant activity & Predicted \\
\hline 1 & 40 & 40 & 80 & $0.265 \pm 0.011$ & 0.267 & $0.309 \pm 0.025$ & 0.311 & $0.177 \pm 0.010$ & 0.179 & $67.0 \pm 2.20$ & 64.6 \\
\hline $2(C)$ & 60 & 60 & 115 & $0.426 \pm 0.035$ & 0.453 & $0.470 \pm 0.018$ & 0.497 & $0.338 \pm 0.018$ & 0.365 & $80.0 \pm 7.05$ & 79.5 \\
\hline 3 & 40 & 40 & 150 & $0.274 \pm 0.014$ & 0.286 & $0.318 \pm 0.021$ & 0.330 & $0.186 \pm 0.008$ & 0.198 & $66.2 \pm 4.72$ & 65.4 \\
\hline 4 & 80 & 80 & 80 & $0.191 \pm 0.002$ & 0.233 & $0.235 \pm 0.017$ & 0.277 & $0.103 \pm 0.011$ & 0.145 & $52.0 \pm 7.76$ & 55.2 \\
\hline $5(C)$ & 60 & 60 & 115 & $0.396 \pm 0.005$ & 0.453 & $0.440 \pm 0.016$ & 0.497 & $0.308 \pm 0.017$ & 0.365 & $79.5 \pm 2.30$ & 79.5 \\
\hline $6(C)$ & 60 & 60 & 115 & $0.436 \pm 0.017$ & 0.453 & $0.480 \pm 0.007$ & 0.497 & $0.348 \pm 0.019$ & 0.365 & $77.0 \pm 3.82$ & 79.5 \\
\hline 7 & 80 & 40 & 150 & $0.234 \pm 0.008$ & 0.247 & $0.278 \pm 0.014$ & 0.291 & $0.146 \pm 0.009$ & 0.159 & $55.4 \pm 1.81$ & 57.19 \\
\hline 8 & 80 & 40 & 80 & $0.222 \pm 0.012$ & 0.247 & $0.266 \pm 0.011$ & 0.291 & $0.134 \pm 0.014$ & 0.159 & $55.0 \pm 2.30$ & 55.4 \\
\hline 9 & 40 & 80 & 150 & $0.347 \pm 0.011$ & 0.376 & $0.391 \pm 0.014$ & 0.420 & $0.259 \pm 0.012$ & 0.288 & $71.0 \pm 3.01$ & 73.14 \\
\hline 10 & 40 & 80 & 80 & $0.295 \pm 0.007$ & 0.335 & $0.339 \pm 0.017$ & 0.380 & $0.207 \pm 0.011$ & 0.247 & $69.0 \pm 5.56$ & 69.75 \\
\hline 11 & 80 & 80 & 150 & $0.204 \pm 0.019$ & 0.255 & $0.244 \pm 0.006$ & 0.296 & $0.116 \pm 0.007$ & 0.167 & $54.7 \pm 4.12$ & 59.59 \\
\hline $12(C)$ & 60 & 60 & 115 & $0.474 \pm 0.010$ & 0.453 & $0.518 \pm 0.026$ & 0.497 & $0.386 \pm 0.016$ & 0.365 & $78.0 \pm 2.69$ & 79.5 \\
\hline 13 & 86.32 & 60 & 115 & $0.188 \pm 0.015$ & 0.213 & $0.232 \pm 0.019$ & 0.247 & $0.100 \pm 0.011$ & 0.105 & $51.0 \pm 1.88$ & 53.5 \\
\hline $14(C)$ & 60 & 60 & 115 & $0.466 \pm 0.008$ & 0.453 & $0.510 \pm 0.013$ & 0.497 & $0.378 \pm 0.017$ & 0.365 & $80.4 \pm 3.27$ & 79.5 \\
\hline 15 & 60 & 60 & 161.06 & $0.480 \pm 0.017$ & 0.454 & $0.524 \pm 0.019$ & 0.498 & $0.392 \pm 0.020$ & 0.366 & $83.0 \pm 4.61$ & 79.7 \\
\hline 16 & 60 & 86.32 & 115 & $0.536 \pm 0.014$ & 0.464 & $0.580 \pm 0.018$ & 0.507 & $0.448 \pm 0.015$ & 0.376 & $87.0 \pm 3.55$ & 84.8 \\
\hline 17 & 60 & 60 & 68.93 & $0.456 \pm 0.018$ & 0.434 & $0.500 \pm 0.015$ & 0.478 & $0.368 \pm 0.013$ & 0.346 & $75.0 \pm 2.70$ & 77.1 \\
\hline 18 & 60 & 33.67 & 115 & $0.403 \pm 0.018$ & 0.426 & $0.447 \pm 0.008$ & 0.470 & $0.315 \pm 0.010$ & 0.338 & $73.0 \pm 3.29$ & 75.2 \\
\hline 19 & 33.67 & 60 & 115 & $0.244 \pm 0.014$ & 0.285 & $0.288 \pm 0.017$ & 0.317 & $0.156 \pm 0.016$ & 0.188 & $58.0 \pm 1.77$ & 60.9 \\
\hline $20(C)$ & 60 & 60 & 115 & $0.460 \pm 0.010$ & 0.453 & $0.504 \pm 0.017$ & 0.497 & $0.372 \pm 0.019$ & 0.365 & $79.5 \pm 2.11$ & 79.5 \\
\hline
\end{tabular}


solution was added to cover the flask surface, which was then left at room temperature for 3 min until most of the cells detached. Subsequently, $10 \mathrm{~mL}$ of the complete medium was added. For the MTT assay, the cell medium $(100 \mu \mathrm{L})$ containing various concentrations of the extract $(20,40,60,80,100$, and $120 \mu \mathrm{g} / \mathrm{mL})$ was added into all the wells and incubated in a $37^{\circ} \mathrm{C}, 5 \% \mathrm{CO}_{2}$ incubator for $72 \mathrm{~h}$. A stock solution of MTT in PBS (5 mg/mL) was prepared and the MTT reagent $(20 \mu \mathrm{L})$ was added to the cell monolayer. DMSO (dimethyl sulfoxide) $(100 \mu \mathrm{L})$ was added to each well and mixed thoroughly by pipetting 10-20 times to dissolve the blue formazan crystals. The absorbance of samples was read at $570 \mathrm{~nm}$ using an ELISA reader [20].

\section{Experimental design and statistic analysis}

RSM software with the central composite experimental design (3-level, 3-factorial) was used to investigate and validate the extraction parameters affecting the extraction yields of catechin $\left(Y_{1}\right)$, myricetin $\left(Y_{2}\right)$, quercetin $\left(Y_{3}\right)$, and antioxidant activity $\left(\mathrm{Y}_{4}\right)$ of curry leaf extracts. In this study, 20 experiments were designed and carried out in duplicate with different ranges of ultrasonic power, methanol concentration, and extraction temperature, which are presented in Table 1 . In order to conduct the experimental design and statistical analysis, Design Expert software (version 6.0) was used. A model was applied to predict the response variables as given below:

$$
\begin{aligned}
Y= & b_{0}+b_{1} X_{1}+b_{2} X_{2}+b_{3} X_{3}+b_{1}^{2} X_{1}^{2}+b_{2}^{2} X_{2}^{2} \\
& +b_{3}^{2} X_{3}^{2}+b_{1} b_{2} X_{1} X_{2}+b_{1} b_{3} X_{1} X_{3}+b_{2} b_{3} X_{2} X_{3}
\end{aligned}
$$

Where $Y$ is the predicted dependent variable; $\mathrm{b}_{0}$ is a constant that fixes the response at the central point of the experiment; $b_{1}, b_{2}$ and $b_{3}$ are the regression coefficients for the linear effect terms; $b_{1} b_{2}, b_{1} b_{3}$ and $b_{2} b_{3}$ are the interaction effect terms and $b_{1}{ }^{2}, b_{2}{ }^{2}$ and $b_{3}{ }^{2}$ are the quadratic effect terms; respectively.

Analysis of variance (ANOVA) and response surface analysis were used to determine the statistical significance of the model. The adequacy of the model was predicted through the ANOVA $(P<0.05)$ and regression analysis $\left(R^{2}\right)$. The relationship between the response and independent variables was demonstrated using a response surface plot.

\section{Results and discussion}

Statistical significance analysis, response surface and model fitting of catechin extraction

The results of the response surface methodology demonstrated significant $(P<0.05)$ regression relationships between catechin and independent variables. The highest and lowest contents of catechin in the curry leaf extracts were obtained using treatments 12 and 13, respectively, with the respective values of 0.477 and $0.188 \mathrm{mg} / \mathrm{g} \mathrm{DW}$ (Table 1). The results indicated significant $(P<0.01)$ quadratic and linear effects of the extraction temperature on catechin content (Table 2). The value of catechin decreased by about $12.8 \%$ when the concentration of methanol increased from $40 \%$ to $80 \%\left(80^{\circ} \mathrm{C}, 150 \mathrm{~W}\right)$ (Figure 1A). The yield of catechin attained the peak value $(0.536 \mathrm{mg} / \mathrm{g} \mathrm{DW})$ at $86.3 \%$ methanol concentration at an extraction temperature of $60^{\circ} \mathrm{C}$. Increasing the ultrasonic power from 80 to $150 \mathrm{~W}$ increased the content of catechin by about $6 \%\left(80^{\circ} \mathrm{C}, 80 \%\right.$ methanol $)$. The predicted model developed for catechin $\left(\mathrm{Y}_{1}\right)$ was as follows:

$$
\begin{aligned}
Y_{1}= & +0.45-0.035 X_{1}+0.019 X_{2}+0.010 X_{3} \\
& -0.020 X_{1} X_{2}-0.0045 X_{1} X_{3}+0.0055 X_{2} X_{3} \\
& -0.15 X_{1}^{2}-0.00832 X_{2}^{2}-0.009193 X_{3}^{2}
\end{aligned}
$$

Analysis of variance for predicted models implied that the model was highly significant (F-value $20.13, P<0.0001$ ) with a good coefficient of determination $\left(R^{2}=0.98\right)$. In addition, lack-of-fit (F-value 1.77, $P>0.05$ ) was not significant (Table 3). For a good model development by RSM, although the lack-of-fit must not be significant, the model must be significant [21].

\section{Statistical significance analysis, response surface and model fitting of myricetin extraction}

The extraction of myricetin was significantly $(P<0.01)$ influenced by the temperature. The highest and lowest contents of myricetin in the curry leaf extracts were obtained using treatments 16 and 13, respectively, with the respective values of 0.58 and $0.233 \mathrm{mg} / \mathrm{g} \mathrm{DW}$. On increasing the temperature from 40 to $56^{\circ} \mathrm{C}(80 \%$ methanol $150 \mathrm{~W})$, the myricetin content increased by about $24.6 \%$. On further increasing the extraction temperature from 56 to $80^{\circ} \mathrm{C}$, similar to the trend observed for catechin, the content of myricetin decreased significantly by about $37.5 \%$ (Figure 1B). Increasing the ultrasonic power from 80 to $150 \mathrm{~W}$ increased the content of myricetin in the extract by about $3.8 \%\left(80^{\circ} \mathrm{C}, 80 \%\right.$ methanol), but no significant effect was found. The predicted model obtained for myricetin $\left(\mathrm{Y}_{2}\right)$ was as follows:

$$
\begin{aligned}
Y_{2}= & +0.50-0.036 X_{1}+0.0189 X_{2}+0.0099 X_{3} \\
& -0.021 X_{1} X_{2}-0.005 X_{1} X_{3}+0.005 X_{2} X_{3} \\
& -0.15 X_{1}^{2}-0.008467 X_{2}^{2}-0.009333 X_{3}^{2}
\end{aligned}
$$

Analysis of variance for predicted models implied that the model was highly significant (F-value 19.77, $P<0.0001)$ with a good coefficient of determination $\left(\mathrm{R}^{2}=0.97\right)$. In addition, lack-of-fit (F-value $\left.1.85, P>0.05\right)$ was not significant. 
Table 2 ANOVA for response surface models of all independent variables

\begin{tabular}{|c|c|c|c|c|c|c|c|c|}
\hline \multirow[t]{3}{*}{ Factor } & \multicolumn{2}{|c|}{ Catechin } & \multicolumn{2}{|c|}{ Myricetin } & \multicolumn{2}{|c|}{ Quercetin } & \multicolumn{2}{|c|}{ DPPH } \\
\hline & Mean & p-value & Mean & p-value & Mean & p-value & Mean & p-value \\
\hline & Square & Prob $>F$ & Square & Prob $>F$ & Square & Prob $>F$ & Square & Prob $>F$ \\
\hline Model & 0.0225 & $<0.0001^{* *}$ & 0.0226 & $<0.0001^{* *}$ & 0.0225 & $<0.0001^{* *}$ & 244.3220 & $0.0001^{* *}$ \\
\hline \multicolumn{9}{|c|}{ Linear term } \\
\hline$X_{1}$ & 0.0142 & $0.0060^{* *}$ & 0.0145 & $0.0061^{* *}$ & 0.0142 & $0.0060^{* *}$ & 372.0941 & $0.0006^{* *}$ \\
\hline$x_{2}$ & 0.0041 & 0.0873 & 0.0040 & 0.0954 & 0.0041 & 0.0873 & 40.4155 & 0.1258 \\
\hline$x_{3}$ & 0.0012 & 0.3259 & 0.0011 & 0.3466 & 0.0012 & 0.3259 & 19.1805 & 0.2749 \\
\hline \multicolumn{9}{|c|}{ Quadratic } \\
\hline$x_{1}^{2}$ & 0.1637 & $<0.0001^{* *}$ & 0.1640 & $<0.0001^{* *}$ & 0.1637 & $<0.0001^{* *}$ & 1599.0550 & $<0.0001^{* *}$ \\
\hline$x_{2}^{2}$ & 0.0005 & 0.5309 & 0.0005 & 0.5285 & 0.0005 & 0.5309 & 2.2023 & 0.7028 \\
\hline$X_{3}^{2}$ & 0.0006 & 0.4902 & 0.0006 & 0.4883 & 0.0006 & 0.4902 & 8.9640 & 0.4472 \\
\hline \multicolumn{9}{|c|}{ Interactions } \\
\hline$x_{1} x_{2}$ & 0.0034 & 0.1168 & 0.0035 & 0.1126 & 0.0034 & 0.1168 & 13.7813 & 0.3502 \\
\hline$x_{1} x_{3}$ & 0.0002 & 0.7122 & 0.0002 & 0.6853 & 0.0002 & 0.7122 & 0.4513 & 0.8624 \\
\hline$x_{2} x_{3}$ & 0.0002 & 0.6527 & 0.0002 & 0.6853 & 0.0002 & 0.6527 & 3.2513 & 0.6436 \\
\hline
\end{tabular}

Independent variable $\mathrm{X}_{1}$ : Temperature, $\mathrm{X}_{2}$ : Mthanol concentration, $\mathrm{X}_{3}$ : Ultrasonic power; ${ }^{* *}$ Significant at $P<0.01$.

A

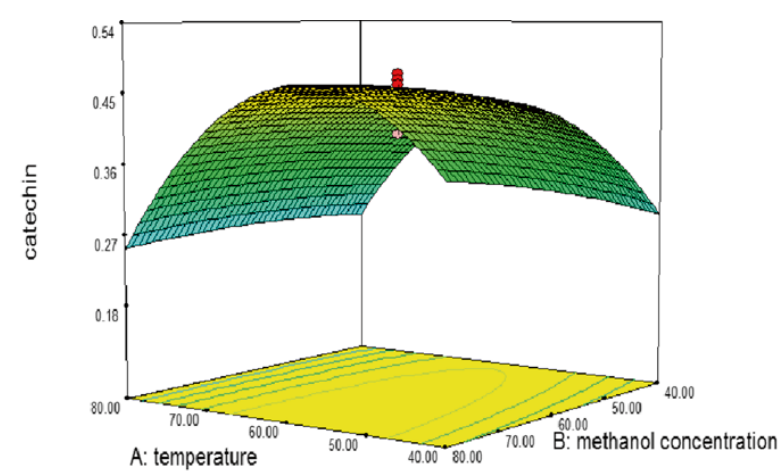

C

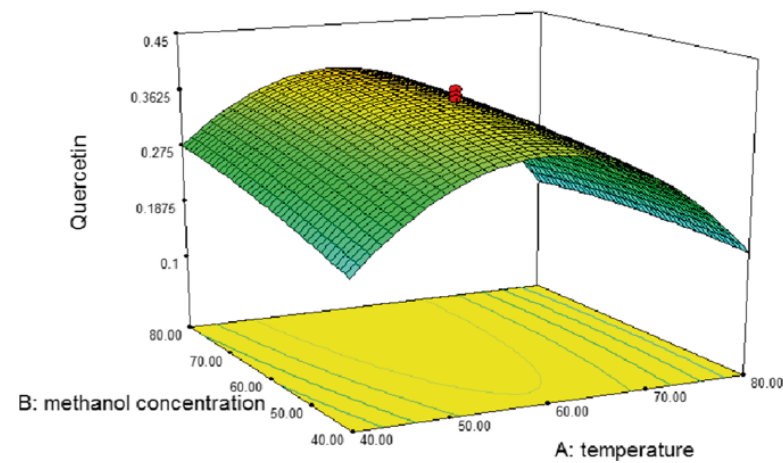

B

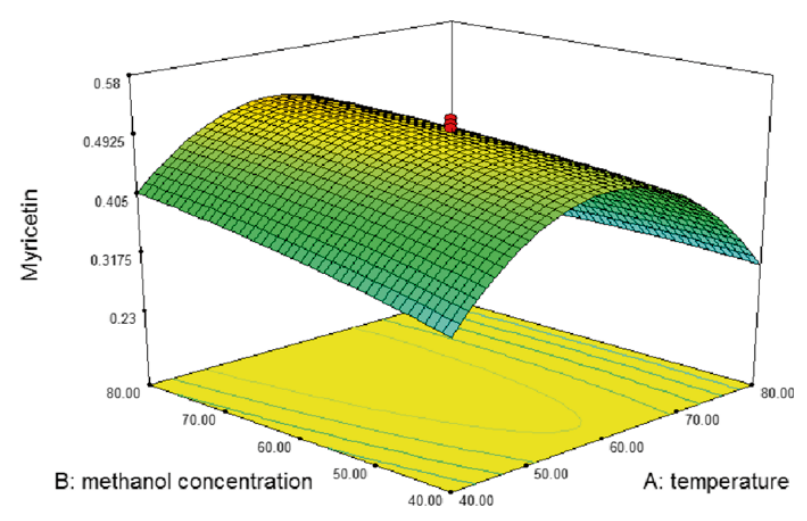

D

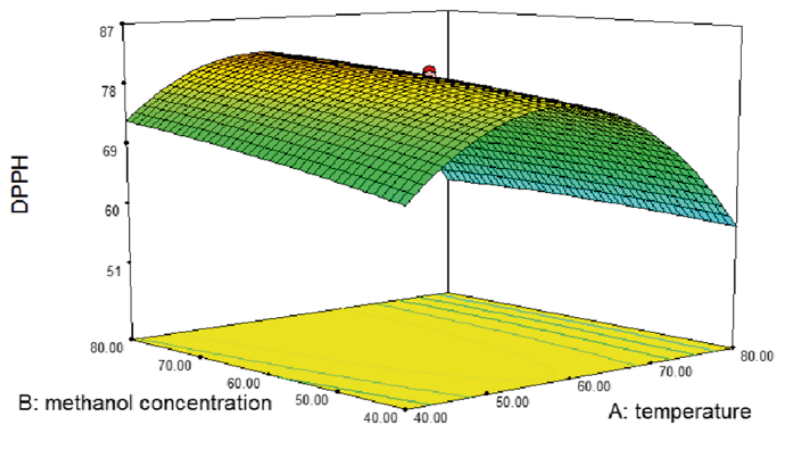

Figure 1 Effect of methanol concentration $(\%)$ and temperature $\left({ }^{\circ} \mathrm{C}\right)$ on the extraction yield of catechin $(\mathrm{A})$, myricetin $(\mathrm{B})$, and quercetin (C), and antioxidant activity (D) at an ultrasonic power of $115 \mathrm{~W}$. 
Table 3 Statistical parameters calculated after implementation of 2 nd full factorial central composite experimental design

\begin{tabular}{lcccccc}
\hline Regression coefficient & $\mathbf{R}^{\mathbf{2}}$ & $\mathbf{R}^{\mathbf{2}}$ (adjusted) & $\boldsymbol{F}$-value of model & Regression $(\boldsymbol{P}$-value) & Lack of fit (F-value) & Lack of fit $(\boldsymbol{P}$-value) \\
\hline$Y_{1}$ & 0.98 & 0.97 & 20.13 & 0.0001 & 1.77 & 0.299 \\
$Y_{2}$ & 0.97 & 0.95 & 19.77 & 0.0001 & 1.85 & 0.289 \\
$Y_{3}$ & 0.99 & 0.99 & 21.48 & 0.0001 & 1.94 & 0.274 \\
$Y_{4}$ & 0.99 & 0.99 & 17.21 & 0.0001 & 1.61 & 0.261 \\
\hline
\end{tabular}

\section{Statistical significance analysis, response surface and} model fitting of quercetin extraction

The highest and lowest contents of quercetin in the curry leaf extracts were obtained using treatment 16 and 13 , respectively, with the respective values of 0.448 and $0.1 \mathrm{mg} / \mathrm{g} \mathrm{DW}$ (Table 1 ). The extraction temperature had significant $(P<0.01)$ quadratic and linear effects on the quercetin content, whereas the effect of methanol concentration and ultrasonic power was not significant. As shown in Figure $1 \mathrm{C}$, the quercetin content increased with increasing methanol concentration. Increasing the temperature from 40 to $58^{\circ} \mathrm{C}$ enhanced the quercetin content; however, further increasing the temperature to $80^{\circ} \mathrm{C}$ led to a significant decrease in the quercetin content. The predicted model obtained for the extraction yield of quercetin $\left(\mathrm{Y}_{3}\right)$ was as follows:

$$
\begin{aligned}
Y_{3}= & +0.37-0.035 X_{1}+0.0201 X_{2}+0.010 X_{3} \\
& -0.020 X_{1} X_{2}-0.0045 X_{1} X_{3}+0.0055 X_{2} X_{3} \\
& -0.15 X_{1}^{2}-0.008327 X_{2}^{2}-0.009193 X_{3}^{2}
\end{aligned}
$$

Analysis of variance for predicted models implied that the model was highly significant (F-value $21.48, P<0.0001$ ) with a good coefficient of determination $\left(R^{2}=0.99\right)$. In addition, lack-of-fit (F-value 1.94, $P>0.05$ ) was not significant (Table 3). The UHPLC chromatogram of the identified flavonoid compounds from the curry leaf extract is shown in Figure 2.

Degradation of the flavonoid and phenolic compounds has been observed with the use of high temperatures [22]. In addition, the Maillard reaction may occur at high temperatures, forming undesired compounds [23,24].
Decreasing the flavonoid concentration in the extract at high temperatures by ultrasound-assisted extraction could be related to the degradation of these compounds at higher temperatures $\left(>56^{\circ} \mathrm{C}\right)$. Pingret et al. [25] reported that the formation of degradation products increased owing to the treatment performed with a titanium horn in the ultrasound process. Chemat et al. [6] demonstrated that the flavor and composition of some edible oils such as hexanal and limonene are deteriorated by the ultrasound treatment $(150 \mathrm{~W})$.

\section{Statistical significance analysis, response surface and model fitting of antioxidant activity}

As shown in Table 2, the DPPH activity of all extracts was more than $51 \%$. The DPPH activity of the extract ranged from $51 \%$ to $87 \%$ when treatments 13 and 16 were employed, respectively. Independent variables showed significant effect on the antioxidant activity of the extracts with a good regression equation $\left(P<0.05, \mathrm{R}^{2}=0.99\right)$ (Table 3 ). The antioxidant activity decreased in the curry leaf extracts on increasing the temperature from 56 to $80^{\circ} \mathrm{C}$, decreasing the methanol concentration from $80 \%$ to $40 \%$, and decreasing the ultrasonic power from 150 to $80 \mathrm{~W}$ (Figure 1D). The extraction variables showed significant $(P<0.01)$ quadratic and linear effects on the antioxidant activity (Table 2 ). The predicted model obtained for DPPH $\left(\mathrm{Y}_{4}\right)$ was as follows:

$$
\begin{aligned}
Y_{4}= & +79.56-5.70 X_{1}+1.88 X_{2}+1.29 X_{3}-1.31 X_{1} X_{2} \\
& +0.24 X_{1} X_{3}+0.64 X_{2} X_{3}-15.29 X_{1}^{2}-0.57 X_{2}^{2}-1.14 X_{3}^{2}
\end{aligned}
$$

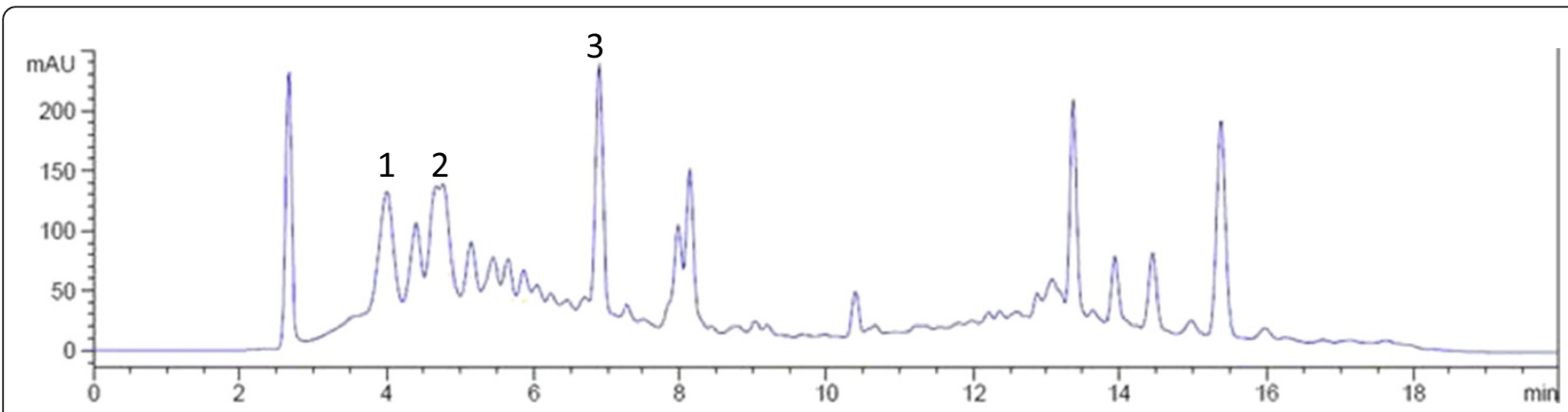

Figure 2 UHPLC chromatogram of curry leaf extract. Identified compounds are: catechin (1), myricetin (2) and quercetin (3). 
Analysis of variance for predicted models implied that the model was highly significant (F-value 17.21, $P<0.0001)$ with a good coefficient of determination $\left(\mathrm{R}^{2}=0.98\right)$. Moreover, lack-of-fit (F-value 1.61, $\left.P>0.05\right)$ was not significant (Table 3).

\section{Optimization of responses}

Numerical optimizations and multiple graphical plots have been conducted in order to establish the optimum level of independent variables with desirable response goals. In the current study, for all responses only one optimal condition was obtained: $55.9^{\circ} \mathrm{C}$ temperature, 80\% methanol, and 145.49 W ultrasonic power (Figure 3). After using the optimum conditions for extraction, the predicted values for catechin, narengine, quercetin, and the antioxidant activity were $0.476,0.519,0.388 \mathrm{mg} / \mathrm{g}$ DW, and $82.4 \%$, respectively.

\section{Verification of the ultrasound-assisted extraction model}

An experiment was conducted to verify the adequacy of the developed extraction model with the predicted optimum treatment conditions $\left(55.9^{\circ} \mathrm{C}, 80 \%\right.$ methanol, and $145.49 \mathrm{~W})$. Under these conditions, the obtained concentration of catechin, narengine, quercetin, and the antioxidant activity were $0.482,0.517,0.394 \mathrm{mg} / \mathrm{g} \mathrm{DW}$, and $83 \%$, respectively. The results of response surface analysis for catechin, myricetin, quercetin, and the antioxidant activity were verified by comparing the predicted values with the experimental values. The obtained results from verification experiment were in consent with the predicted values, because an insignificant $(P>0.05)$ difference was observed between the verification experimental and the predicted values.

\section{Evaluation of anticancer activity of optimized and unoptimized curry leaf extract}

Optimized and unoptimized curry leaf extracts were used in order to evaluate their anticancer activity against HeLa cancer cell lines. Preliminary screening showed that the curry leaf extracts exhibited a significant anticancer activity against HeLa cancer cells at a concentration of $80 \mu \mathrm{g} / \mathrm{mL}$, with an inhibition rate of $51.1 \%$ and $56.8 \%$ from the unoptimized and optimized extracts, respectively (Figure 4A). Tamoxifen (positive control) at a concentration of $80 \mu \mathrm{g} / \mathrm{mL}$, showed $79.1 \%$ inhibition of HeLa cells. Furthermore, optimization of the reflux curry leaf extraction enhanced the anticancer activity by about $16.1 \%$. The half maximal inhibitory concentration $\left(\mathrm{IC}_{50}\right)$ values of the optimized and unoptimized extracts were found at concentrations of 67.2 and $81.8 \mu \mathrm{g} / \mathrm{mL}$, respectively. As shown in Figure 3, the normal cells treated with the optimized and unoptimized extract of curry leaves showed $69.9 \%$ and $68.4 \%$ viability, respectively. According to the obtained results, optimized and unoptimized curry leaf extracts showed nontoxic effects at concentrations below $112 \mu \mathrm{g} / \mathrm{mL}$, but toxic effects of the curry leaf

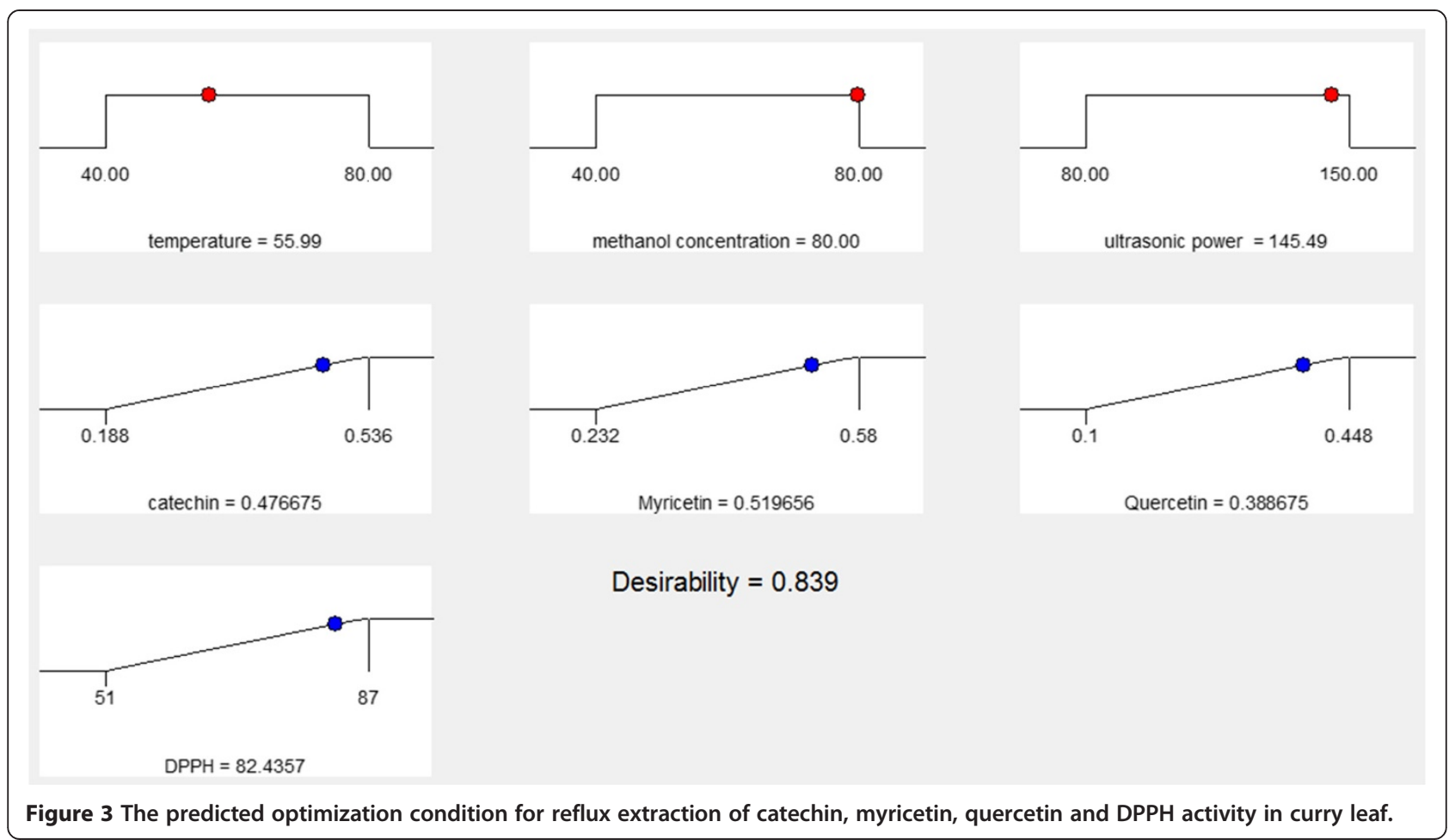



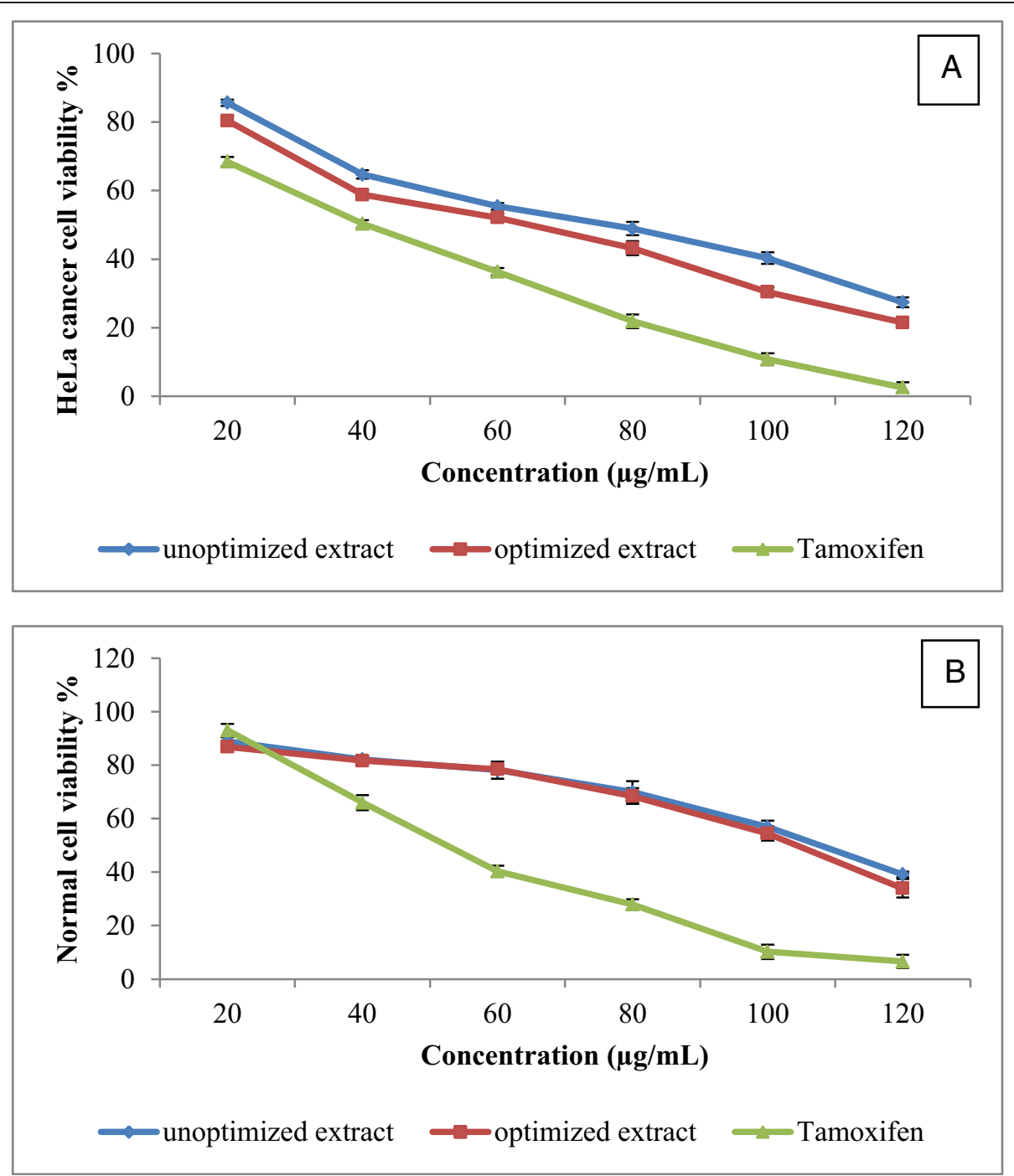

Figure 4 Dose-dependent anticancer activity of curry leaf extracts against HeLa cell line (A) and normal cell viability (B). Tamoxifen was used as a positive control. Bars represent standard error of means.

extracts were observed at concentrations higher than that. Naik et al. [26] reported M. koenigii is more toxic to the mouse macrophages because of the high alkaloid content. The antioxidant and anticancer activities of the herbal extracts are directly related to phytochemicals or secondary metabolites of the extract $[27,28]$.

This study confirmed that anticancer activity of curry leaf extracts is associated with amount of potent flavonoid compounds because the highest anticancer activity was observed from the optimized extract, which contained higher amounts of flavonoids than the unoptimized extracts. Increased activation in the DPPH assay from the optimized extracts corroborates these earlier findings. The anticancer activity of curry leaf extracts against MDA-MB-231 and MCF-7 cell lines (breast cancer) has been reported previously $[15,29,30]$. The anticancer activity of curry leaves against HeLa cancer cells and the effective dose of this extract have been scarcely reported. Therefore, the findings of this current study could be useful for future studies.

The reduced cost of extraction is clearly advantageous for the proposed ultrasound-assisted extraction method in terms of time, energy, and the enhanced final yield [31]. Conventional procedures such as reflux and maceration are often time and energy consuming, and are generally not always interesting from the industrial point of view. Among the others, many advantages can be pointed out when taking into account the ultrasound-assisted extraction of flavonoids from curry leaves, including fast procedure, reduction of experimental cost (time needed, energy required, equipment size), and no need for any additional treatment or chemicals to complete the experiments. 


\section{Conclusions}

In this study, ultrasound-assisted extraction of catechin, narengine, and quercetin, and the antioxidant activity of curry leaf extracts were successfully optimized using RSM. The results indicate that the ultrasonic power, methanol dilution, and extraction temperature significantly affect the extraction yields of flavonoids with consequent enhancement of the antioxidant and anticancer activities of the extracts. The results can be easily explained by considering that both the temperature and methanol content have a positive effect on the solubility of flavonoids in the extraction solution. The ANOVA results revealed that the extraction temperature is the most significant factor influencing the response variables investigated. It was found that an ultrasonic power of $145.52 \mathrm{~W}$ at $55.9^{\circ} \mathrm{C}$ with $80 \%$ methanol was the appropriate condition for the extraction of catechin, narengine, and quercetin from curry leaves, with the consequent high anticancer and antioxidant activities. The optimized extract showed a more distinct scavenging activity against DPPH and significant anticancer activities against HeLa cancer cell lines at a concentration of $67.2 \mu \mathrm{g} / \mathrm{mL}$, without toxicity to normal cells. Thus, it could be concluded that flavonoids of the curry leaves contributed to the anticancer activity of the extracts.

\section{Competing interests}

The authors declare that they have no competing interests.

\section{Authors' contributions}

Study design and experimental work was by AG under the supervision of HJ. First draft of paper was written by AG and reviewed by HJ. AR and EK contributed in antioxidant and anticancer experiment and analysis. All authors reviewed and approved the final version.

\section{Acknowledgements}

The authors would like to thank the Ministry of Higher Education Malaysia and the Research Management Centre, University Putra Malaysia (UPM) for sponsoring this work. This paper was part of post doctoral project (Development of Malaysian Herbal Monograph).

\section{Author details}

'Department of Crop Science, Faculty of Agriculture, University Putra Malaysia, 43400 Serdang, Selangor, Malaysia. ${ }^{2}$ Department of Nutrition \& Dietetics, Faculty of Medicine \& Health Sciences, University Putra Malaysia, 43400 UPM Serdang, Selangor, Malaysia.

Received: 2 June 2014 Accepted: 21 August 2014

Published: 28 August 2014

\section{References}

1. Atoui AK, Mansouri A, Boskou G, Kefalas P: Tea and herbal infusions: their antioxidant activity and phenolic profile. Food Chem 2005, 89(1):27-36

2. Park SJ, Myoung H, Kim YY, Paeng JY, Park JW, Kim MJ, Hong SM: Anticancer effects of genistein, green tea catechins, and cordycepin on oral squamous cell carcinoma. J Korean Assoc Oral Maxillofac Surg 2008, 34(1):1-10.

3. Ghasemzadeh A, Jaafar HZ, Karimi E: Involvement of salicylic acid on antioxidant and anticancer properties, anthocyanin production and chalcone synthase activity in ginger (Zingiber officinale Roscoe) varieties. Int J Mol Sci 2012, 13(11):14828-14844.

4. Bak M-J, OK S, Jun M, Jeong W-S: 6-shogaol-rich extract from ginger up-regulates the antioxidant defense systems in cells and mice. Molecules 2012, 17(7):8037-8055.
5. Khoddami A, Wilkes MA, Roberts TH: Techniques for analysis of plant phenolic compounds. Molecules 2013, 18(2):2328-2375.

6. Chemat F, Grondin I, Costes P, Moutoussamy L, Sing A, Smadja J: High power ultrasound effects on lipid oxidation of refined sunflower oil. Ultrason Sonochem 2004, 11(5):281-285.

7. Chemat F, Khan MK: Applications of ultrasound in food technology: processing, preservation and extraction. Ultrason Sonochem 2011, 18(4):813-835.

8. Sultana B, Anwar F, Ashraf M: Effect of extraction solvent/technique on the antioxidant activity of selected medicinal plant extracts. Molecules 2009, 14(6):2167-2180

9. Lapornik B, ProÅjek M, Golc Wondra A: Comparison of extracts prepared from plant by-products using different solvents and extraction time. J Food Eng 2005, 71(2):214-222.

10. Kuo C-H, Hsiao F-W, Chen J-H, Hsieh C-W, Liu Y-C, Shieh C-J: Kinetic aspects of ultrasound-accelerated lipase catalyzed acetylation and optimal synthesis of $4 \hat{a} €^{2}$-acetoxyresveratrol. Ultrason Sonochem 2013, 20(1):546-552

11. Gu F, Xu F, Tan L, Wu H, Chu Z, Wang Q: Optimization of enzymatic process for vanillin extraction using response surface methodology. Molecules 2012, 17(8):8753-8761.

12. Jain SK, DeFilipps RA: Medicinal plants of India: Reference Publications. 1991.

13. Ito C, Itoigawa M, Nakao K, Murata T, Tsuboi M, Kaneda N, Furukawa H: Induction of apoptosis by carbazole alkaloids isolated from Murraya koenigii. Phytomedicine 2006, 13(5):359-365.

14. Mohd Nor F, Suhaila M, Nor Aini I, Razali I: Antioxidative properties of Murraya koenigii leaf extracts in accelerated oxidation and deep-frying studies. Int J Food Sci Nutr 2009, 60(S2):1-11.

15. Ghasemzadeh A, Jaafar HZ, Rahmat A, Devarajan T: Evaluation of Bioactive Compounds, Pharmaceutical Quality, and Anticancer Activity of Curry Leaf (Murraya koenigii L.). Evid Based Complement Alternat Med 2013, 2014:873803.

16. Muthumani $P$, Venkatraman $S$, Ramseshu K, Meera R, Devi $P$, Kameswari B, Eswarapriya B: Pharmacological studies of anticancer, anti inflammatory activities of Murraya koenigii (Linn) Spreng in experimental animals. In Vitro 2009, 17:18.

17. Dineshkumar B, Mitra A, Mahadevappa M: Antidiabetic and hypolipidemic effects of mahanimbine (carbazole alkaloid) from murraya koenigii (rutaceae) leaves. Int J Phytomed 2010, 2(1):22-30.

18. Tembhurne S, Sakarkar D: Hypoglycemic effects of fruit juice of Murraya koenigii (L) in alloxan induced diabetic mice. Int J Pharm Tech Res 2009, 1(4):1589-1593.

19. Mensor LL, Menezes FS, Leitão GG, Reis AS, dos Santos TC, Coube CS, Leitão SG: Screening of Brazilian plant extracts for antioxidant activity by the use of DPPH free radical method. Phytother Res 2001, 15(2):127-130.

20. Lau C, Ho C, Kim C, Leung K, Fung K, Tse T, Chan H, Chow M: Cytotoxic activities of Coriolus versicolor (Yunzhi) extract on human leukemia and lymphoma cells by induction of apoptosis. Life Sci 2004, 75(7):797-808.

21. Noordin MY, Venkatesh VC, Sharif S, Elting S, Abdullah A: Application of response surface methodology in describing the performance of coated carbide tools when turning AISI 1045 steel. J Mater Process Technol 2004, 145(1):46-58.

22. Nuutila A, Kammiovirta K, Oksman-Caldentey K-M: Comparison of methods for the hydrolysis of flavonoids and phenolic acids from onion and spinach for HPLC analysis. Food Chem 2002, 76(4):519-525.

23. Sensoy L, Rosen RT, Ho C-T, Karwe MV: Effect of processing on buckwheat phenolics and antioxidant activity. Food Chem 2006, 99(2):388-393.

24. Shi J, Maguer ML, Kakuda Y, Liptay A, Niekamp F: Lycopene degradation and isomerization in tomato dehydration. Food Res Int 1999, 32(1):15-21.

25. Pingret D, Durand GG, Fabiano-Tixier A-S, Rockenbauer A, Ginies C, Chemat F: Degradation of edible oil during food processing by ultrasound: electron paramagnetic resonance, physicochemical, and sensory appreciation. J Agric Food Chem 2012, 60(31):7761-7768.

26. Naik SK, Mohanty S, Padhi A, Pati R, Sonawane A: Evaluation of antibacterial and cytotoxic activity of Artemisia nilagirica and Murraya koenigii leaf extracts against mycobacteria and macrophages. BMC Complement Altern Med 2014, 14(1):87.

27. Kennedy DO, Wightman EL: Herbal extracts and phytochemicals: plant secondary metabolites and the enhancement of human brain function. Adv Nutr 2011, 2(1):32-50.

28. Shabbir M, Khan MR, Saeed N: Assessment of phytochemicals, antioxidant anti-lipid peroxidation and anti-hemolytic activity of extract and various 
fractions of Maytenus royleanus leaves. BMC Complement Altern Med 2013, 13(1):143.

29. Noolu B, Ajumeera R, Chauhan A, Nagalla B, Manchala R, Ismail A: Murraya koenigii leaf extract inhibits proteasome activity and induces cell death in breast cancer cells. BMC Complement Altern Med 2013, 13(1):7.

30. Kok YY, Mooi LY, Ahmad K, Sukari MA, Mat N, Rahmani M, Ali AM: Antitumour promoting activity and antioxidant properties of girinimbine isolated from the stem bark of Murraya koenigii S. Molecules 2012. 17(4):4651-4660

31. Virot M, Tomao V, Le Bourvellec C, Renard CM, Chemat F: Towards the industrial production of antioxidants from food processing by-products with ultrasound-assisted extraction. Ultrason Sonochem 2010, 17(6):1066-1074.

doi:10.1186/1472-6882-14-318

Cite this article as: Ghasemzadeh et al:: Optimization of ultrasoundassisted extraction of flavonoid compounds and their pharmaceutical activity from curry leaf (Murraya koenigii L.) using response surface methodology. BMC Complementary and Alternative Medicine 2014 14:318.

\section{Submit your next manuscript to BioMed Central and take full advantage of:}

- Convenient online submission

- Thorough peer review

- No space constraints or color figure charges

- Immediate publication on acceptance

- Inclusion in PubMed, CAS, Scopus and Google Scholar

- Research which is freely available for redistribution 